\title{
ON THE RELATIONSHIP OF COMPUTING TO THE ARTS AND CULTURE - AN EVOLUTIONARY PERSPECTIVE
}

\author{
George Mallen \\ System Simulation Ltd \\ Burleigh House \\ 28 Tavistock Street \\ London WC2E 7PB \\ UK \\ george@ssl.co.uk
}

Our increasing knowledge of human evolution and of cognitive science combine to provide new insights into the function and roles of that wide variety of skills and products which are gathered under the heading "art". Since all homo sapiens cultures produce it, art is on a par with language and tool making as a fundamental characteristic of what it means to be human. Why do we do it? What is its survival value? Historically it seems that, about the time humans evolved language, tool making skills were diverted into decoration and symbolic representation and thereafter cultural evolution was rapid - from shell shawls to a diamond encrusted skull, from flint axes to the Large Hadron Collider in only 80000 years! Just what is the relationship of computing to the arts and culture in our modern world of externalised, accessible knowledge and rapidly evolving technologies? This paper addresses that question.

\section{THE LONG VIEW}

My goal is a deeper understanding of the place of computer art in the broader scheme of $21^{\text {st }}$ century culture. In the 40 years since the Computer Arts Society was founded not only has the technology evolved at a staggering rate but our knowledge about the world around us and of ourselves has also hugely increased. So my aim is to see how all that new knowledge might illumine the processes begun by encouraging artists to explore computing as an artistic medium.

To do this we need to take a long view of human evolution, the last million years or so from homo erectus to homo sapiens sapiens and then from chipped flints to the Large Hadron Collider in only a quarter of a million years. Of particular importance is that most human of all facilities - being able to imagine and represent non-present things, those products of hand, brain and tool which we call "art". 


\section{CAT 2010 London Conference $\sim 3^{\text {rd }}$ February \\ George Mallen}

The story of life on earth is unfolding as the tools and techniques of palaeontology, anthropology, archaeology and, more recently neurophysiology and cognitive science, develop. Current understanding is that from the formation of the planet some 8 billion years ago for half of that time life has been present - algae 4 billion years ago, shell fish and corals 3 billion years ago, first mammals over 2 billion years ago. Mammalian evolution has continued since then as life adapted into environmental niches. That long evolutionary haul of more than 2 billion years eventually produced our early ancestors, australopithocenes, some 4 million years ago, and then the more clearly established ancestry of homo habilis ( 2 million years ago), homo erectus (1 million years ago) and then throwing up our species, homo sapiens sapiens, so very recently, just 200,000 years ago.

In evolutionary terms from homo habilis to homo sapiens there have been two major spurts of brain growth. The first, between 1 and 2 million years ago, was round about the time of the emergence of homo erectus and probably marks the emergence a new level of sociality, embedding the collaboration needed for successful hunting and gathering and, with that, a more sophisticated "theory of mind", ie recognition that other individuals were capable of similar thought processes to oneself. The second growth spurt was about quarter of a million years ago and seems to mark the emergence of homo sapiens sapiens. However our near cousins, the neanderthals, were also around at this time, at least in Europe and we now know that they had bigger brains than us. Theirs was 1.5 litres whereas homo sapiens have an average brain size of 1.3 litres. So brain size alone is not what gave us whatever evolutionary advantage led to our survival and the extinction of the neanderthals. What then did?

Archaeological evidence indicates that that most recent spurt in brain gowth also marks an increase in the types of tools which humans made. For about 2 million years there had been a slow progress in the development of tools and the things made with them, shelters, garments and containers. Then around 200,000 years ago there is a dramatic increase in the range of things made - very sharp long flints, pots and importantly some evidence of ornament. At this time too language was developing. Stephen Mithen argues in "The Singing Neanderthals" [11] that there was a long period before the emergence of language proper when sounds - socialising hums, grunts of encouragement, warning cries - and gestures were how early hominids communicated. It has also been argued that the loss of body hair meant that infants could no longer cling to their mothers so they had to be set down and baby noises and cooings would be the means of linking mother to child. Thus it is likely that sound and musical noises predate language. The long period of slow evolution of tools corresponds with this pre-language evolution of sound making. Then both these processes change at that interesting point 200,000 years ago when it looks as if sound making reached the point of abstract language and there was a rapid increase in the sophistication of tool 


\section{CAT 2010 London Conference $\sim 3^{\text {rd }}$ February \\ George Mallen}

making. Mithen, in his earlier book "The Prehistory of Mind" [9] argues that this key event in brain development was the point at which hitherto different functional capabilities, for example those for knowing what to eat and what to avoid, the toolmaking abilities already referred to, the social capabilities for working in groups and getting a mate, quite suddenly, through some as yet not understood brain event, became able to influence and communicate with each other. For example the tool making capability could work with the social capability to make things which were symbolic of social relationships, strings of beads, shell shawls, bone and stone "sculptures". It looks as if a new form of brain organisation had appeared by which attention could be allocated to different functions according to awareness and circumstances. Was this "attention organiser" what we now call consciousness, taking over some of the functions previously carried out unconsciously or instinctively?

So the story so far - about 100,000 years ago evolution on our planet had resulted in the human animal equipped with a big brain capable of using sound and music for communication, language, tool making, social collaboration, awareness of self, probably conscious thought and probably the ability to represent things not present, such as remembered images of animals or objects. There were probably around 1 million such individuals mostly in the Africa and the Middle East though with growing evidence of pockets elsewhere.

And there the story almost ended. 73000 years ago a huge volcanic eruption at Mount Toba in Sumatra almost extinguished human kind. The ensuing 10000 years of a dust enshrouded, cold planet brought the population down to a few tens of thousand, some estimates are as low as 15,000 . Whatever capabilities these individuals had for survival these are the characteristics which underpin our modern culture. From that time, when humanity fully emerged from this extreme threat, around 50,000 years ago, the human population has grown seemingly inexorably to its current 6 billion or so. Instead of just finding an ecological niche and living symbiotically within it, as most animals do, the human has used its functional capabilities to spread over the planet and adapt to all but the most extreme environments and, indeed, modify environments to its needs.

The survival capabilities which brought our ancestors through the 10,000 year Toba winter have evidently been more than enough to see the species through subsequent environmental challenges, such as glaciations. My argument is that the human propensities which came from that time are crucial to our understanding of our culture now. I suggest that the functional capabilities of the human animal which were in place around 100,000 years as the key characteristics of homo sapiens led up to what I consider to be a defining characteristic - the ability to externalise internal thoughts and imaginings. Language would have allowed the expression of internal thoughts and needs, the more sophisticated tools could have been used for making marks and the beginnings of drawing and painting, the ability to represent externally something not 


\section{CAT 2010 London Conference $\sim 3^{\text {rd }}$ February \\ George Mallen}

immediately present. The extreme pressures of the environmental cataclysm of Mount Toba would have placed very high value indeed on the ability to externalise and communicate. With a very short life expectancy the ability to teach off-spring the basics of survival would have been paramount. Those who could pass down skills and understandings quickly and effectively would survive, those who couldn't wouldn't! Very soon after the emergence from that cataclysm there is evidence of the exercise of such externalisation and communication skills namely the cave paintings and rock art dating from those times. Such works are still mysterious in their purpose and use, is it possible they were a celebration of a hard won skill which enabled the ancestors to survive?

So our human evolutionary trajectory comes to a focus around 50,000 years ago with the spread of humanity as successful hunter/gatherer across the globe and the beginnings of our modern cultural history. Intervening environmental challenges such as glaciations have been survived and, since the last glaciation which ended about 13,000 years ago, human cultural evolution has been dramatic. The last 10,000 years have seen the transition from hunter/gatherer to agriculture, settlements, division of labour, counting, writing, governance structure, laws, cities, empires, wars, mass religions, science, technology, art and all the stuff that makes modern humanity. Underlying all this are four key human propensities:

1. The propensity to externalise emotion (affect) through sounds, images and words;

2. The propensity to externalise images using hand and tools;

3. The propensity to externalise thoughts using words and other symbols;

4. The propensity to understand/manipulate/empathise with external others using theory of mind

Our modern world is the result of the interworking of these propensities over hundreds of generations and millions of people and are concerned with externalising stuff that is originally in our heads. From these have come the main "organs" of global culture governance, religions, science, art and wealth creation. As with the organs of our biological selves, which are built from proteins expressed by our genes, so these organs of our mass culture are built from the propensities described above which in turn arise from the brain functionalities evolved 100,000 years ago and refined by the near extinction event. There isn't space here to develop the analogy between biological organs and cultural organs, that would take us well into meme territory and must await another discussion. The organs most relevant to this discussion are art and science but we must remember that all the organs, as in our bodies, are interdependent and must all function harmoniously together to provide a healthy totality. Going back to the list of propensities, all are involved in differing proportions in the functioning of the five cultural organs. 
CAT 2010 London Conference $\sim 3^{\text {rd }}$ February
George Mallen

The arts "organ" has produced a rich history of image and object from the interplay of hands and brains with many different tools and technologies. Artists, and here we should remind ourselves of Gombrich's opening statement in "The Story of Art", "There really is no such thing as Art. There are only artists" [5], have sometimes been the servants of church, state or wealth and sometime been freer spirits, exploring the fringes of what's possible. Overall the history of art presents a record of a multitude of things, tangible and intangible, offering endless opportunity for historians and critics to classify and reclassify, interpret and re-interpret. But above all we should remember that the art process is one of externalising, projecting from the mind, using and adapting whatever materials and tools are to hand

In contrast the science "organ" has through the evolution of the evidence based scientific method, tried to build reliable, accessible knowledge repositories. These now tell us about the evolutionary history of human kind, which I have crudely summarised above, but also about the beginning and end of the cosmos, about psychology and biology and brains and everything else. But science is always "work in progress" and the shifting sands of theory and hypothesis can never provide absolute certainty. Nevertheless the scientific method has provided perhaps the only globally successful consensual human endeavour. Though science and technology are often lumped together in the belief that science spawns technical innovation this is an overly simple belief. Certainly the scientific requirement for ever better instruments is a great spur, perhaps the greatest spur, to technological innovation. But it does also seem that the root of the urge to technical innovation goes much deeper, in the propensity to externalise images and thought using hands and tools. The innovations in flint tool making 200,000 years ago were the first sign of the avalanche of innovations which would thenceforth propel human cultural development. At that point art and technology were very closely linked indeed.

\section{COMPUTERS AND ART}

How does all this help us understand the rather curious relationship between computers and the arts? At one level it is fairly straightforward. What the Computer Arts Society has done over the past 40 years has been simply to add the computer to the list of tools available for propensities to externalise images and for communicating emotion and affect. As a result there have been many additions to the list of "things created" and the fact that a significant proportion of these now constitute the beginnings of a national digital art collection at the V\&A [1] signals a recognition of their place in art history. They are there now for historians and critics to mull over and interpret.

However from the overview developed above there is more to it. As we have seen, the last great evolutionary adaptation in brain function 200,000 years ago was the 
hypothesised "attention organiser" which enabled different functional characteristics of natural intelligence to overlap and work together and create self awareness and consciousness as we now know it. Today, especially after the apparent failure of the Copenhagen climate change conference, it is clear that the "organs of culture" are not working together. The wealth creation organ pursues its own goals through globalisation and disregard for the environmental and social costs involved. The science organ produces data and knowledge at ever increasing rates which the governance organ seems unable to assimilate and act upon. The governance organ itself seems caught by the conflicting demands for democratic fairness, which requires time to achieve, and the need to respond quickly to threats and challenges. The religious organ seems unable to engage in other than extremist discourse. The arts organ creates its own internal discourses which often baffle outsiders. However of all the organs the breadth of engagement of the science and the arts in creating and adapting new technologies to their communication ends does offer a glimmer of hope. There is, in my view, an urgent need to get all the organs of culture to work together if we are to survive this next looming, self inflicted environmental catastrophe. Can we conceive of a cultural equivalent of the brain adaptation which led to our multi-faceted human intelligence?

I think the answer to that question is "Yes" and that cultural equivalent is the computer. It already has capabilities to support externalised knowledge repositories, to augment natural intelligence, to provide extensive modelling and analytical tools and to provide new social communication channels. Currently the computer has these as separate capabilities, so reminiscent of the separated early human intelligences. All the organs of culture currently use one or other or several of these computing capabilities. It is now a challenge to computer people and artists is to try to work together to create the systems which will enable all the organs of culture to intercommunicate and function as a cybernetic whole.

Stated baldly this is a rather grandiose objective. But it is worth recalling that 40 years ago, in 1969, a group of scientists, computer engineers and artists came together, under the aegis of the Computer Arts Society, and created a system called Ecogame [8] which sought to illustrate how computers might be used in the 1980s. The multimedia, economic game environment which resulted was played by many of the leading industrialists, economists and politicians of the time at the Davos symposiumin 1971. My call now is for a $21^{\text {st }}$ century multi-disciplinary equivalent of the Ecogame project, scaled up appropriately for the current challenges and to help design the collaborative, culturally aware information/knowledge systems needed to see us through. Can we do it? 
CAT 2010 London Conference $\sim 3^{\text {rd }}$ February

George Mallen

\section{References and further reading}

[1] BEDDARD H \& DODDS D Digital Pioneers V\&A Publishing 2009

[2] BOYD B On the Origin of Stories - Evolution, Cognition and Fiction Belknap Harvard 2009

[3] DEUTSCH S A Concise History of Western Music for Film Makers The Soundtrack Vol 2.1, 2009, pp23-38

[4] DUNBAR R The Human Story Faber and Faber 2004

[5] GOMBRICH E H The Story of Art Phaidon Press 1978

[6] HUMPHREY N "Cave Art, Autism and the Evolution of the Human Mind" Journal of Consciousness Studies, Vol 6, 1999

[7] LEWIS-WILLIAMS D The Mind in the Cave Thames \& Hudson 2002

[8] MALLEN G "Bridging Computing in the Arts and Software Development" in White Heat Cold Logic, British Computer Art 1960 -1980 Eds Brown P, Gere C, Lambert N, Mason C, MIT Press 2008

[9] MITHEN S The Prehistory of Mind - The Cognitive Origins of Art and Science Thames \&Hudson 1996

[10] MITHEN S After the Ice Phoenix 2003

[11] MITHEN S The Singing Neanderthals - the Origins of Music, Language, Mind and Body Weidenfeld and Nicholson 2005

[12] SOLSO R L The Psychology of Art and the Evolution of the Conscious Brain MIT Press 2003 